\title{
Preparation and evaluation of chitosan microspheres containing nicorandil
}

\author{
Keyur S Patel, Mandev B Patel ${ }^{1}$ \\ Research Scholar, Department of Pharmaceutics, Bhagwant University, Ajmer, Rajasthan, ${ }^{1}$ A-One Pharmacy College, Enasan, Ahmedabad, \\ Gujarat, India
}

\begin{abstract}
Objectives: The objective of present study was to develop chitosan-based sustained release nicorandil microspheres to reduce the dosing frequency. Materials and Methods: The nicorandil-loaded chitosan microspheres were formulated by emulsion crosslinking method. A $3^{2}$ factorial design was employed to study the influence of drug: Polymer ratio and volume of glutaraldehyde (GA) on percentage entrapment efficiency, particle size, and \% drug release at $8 \mathrm{~h}$. Results: The entrapment efficiency was found to be $41.67 \pm 1.43-77.33 \pm 1.97 \%$ and particle size range $65.67 \pm 2.08-146.67$ $\pm 2.18 \mu \mathrm{m}$. The batch $\mathrm{CH} 5$ showed $79.11 \pm 2.23$ and $96.21 \pm 2.41 \%$ drug release at 8 and $12 \mathrm{~h}$, respectively. Conclusions: Drug: Polymer ratio and volume of GA had significant effect on \% entrapment efficiency, particle size, and \% drug release. From the scanning electron microscopy (SEM) study observed that microspheres were spherical and fairly smooth surface. Fickian diffusion was the mode of drug release from nicorandil-loaded chitosan microspheres formulations.
\end{abstract}

Key words: Chitosan, emulsion crosslinking method, glutaraldehyde, microspheres, nicorandil

\section{INTRODUCTION}

Nicorandil is a nitrate derivative of nicotinamide that is used in the treatment of angina pectoris. It is a potassium channel opener providing vasodilatation of arterioles and large coronary arteries. Its nitrate component produces venous vasodilatation. ${ }^{[1]}$ Nicorandil has an elimination half-life of $1 \mathrm{~h}$, and the therapeutic dose is in the range of 5-40 mg taken twice daily. ${ }^{[2,3]}$ To reduce the frequency of administration and to improve patient compliance, sustained-release formulations of nicorandil are desirable. One of the methods of sustained drug delivery system is by microencapsulation, which is microsphere drug delivery system.

Microspheres have been explored extensively for their use in the field of drug delivery and various polymers have been utilized

\section{Address for correspondence:}

Mr. Keyur S. Patel,

Research Scholar, Bhagwant University, Ajmer,

Rajasthan - 305004 , India.

E-mail: keyur.pharma@gmail.com

\begin{tabular}{|l|l|}
\hline \multicolumn{2}{|c|}{ Access this article online } \\
\hline Quick Response Code: & Website: \\
\hline & www.jpionline.org \\
\cline { 2 - 2 } & DOI: \\
\hline
\end{tabular}

for the formulation of the microspheres, which in turn have been assessed for different purposes. Microspheres are one of the multiple unit dosage forms. Eventually the total dose and few adverse reactions may be reduced since a steady plasma concentration is maintained. Microspheres are potential drug delivery carrier systems in the segment of novel drug delivery and are prepared using assorted polymers. ${ }^{[4,5]}$ Chitosan which is deacetylated derivative of (-4)2-acetamido-2-deoxy-b-dglucose or chitin has been extensively explored for its various biomedical and pharmaceutical applications. Properties such as biodegradability, low toxicity, and good biocompatibility make it suitable for use in drug delivery and biomedical field. As a drug carrier, chitosan has been investigated for the sustained delivery of many oral formulations and parenteral formulations. ${ }^{[6]}$ Chitosan microspheres have been prepared by emulsion crosslinking, ion-induced coagulation, and spraydrying methods. Of these methods, the most common method used to prepare chitosan microspheres is the emulsion chemical crosslinking method. ${ }^{[7]}$ There are numerous reports on the use of glutaraldehyde (GA) as a crosslinking agent in the preparation of microspheres. ${ }^{[8,9]}$ The chemical crosslinking method for preparation of chitosan microspheres involves emulsification followed by crosslinking with a suitable crosslinking agent (e.g., GA). The aim of this study was to prepare chitosan microspheres containing nicorandil by emulsion chemical crosslinking method to achieve a controlled drug release profile and to study the effect of different formulation variables such as drug:polymer ratio and GA on particle size, encapsulation efficiency, and its in vitro release behavior. 


\section{MATERIALS AND METHODS}

\section{Materials}

Nicorandil was obtained as a gift sample from Torrent Research Center. Chitosan was procured from Yarrow Chemicals Limited. Liquid paraffin, acetic acid, and Span 80 were purchased from RFCL. GA was purchased from Estron Chemicals.

Drug and excipient compatibility study by differential scanning calorimetry (DSC)

The DSC study was carried out using DSC-60 (Shimadzu Corporation, Japan). The instrument comprises of calorimeter, flow controller, thermal analyzer, and operating software. The samples were heated in sealed aluminum pans under air flow $(30 \mathrm{ml} / \mathrm{min})$ at a scanning rate of $10^{\circ} \mathrm{C} / \mathrm{min}$ from 35 to $250^{\circ} \mathrm{C}$. Empty aluminum pan was used as a reference. The heat flow as a function of temperature was measured for the samples.

\section{Preparation of microspheres}

Weigh amount chitosan and $150 \mathrm{mg}$ of drug was dissolved in $15 \mathrm{ml} \mathrm{5 \%}$ acetic acid. The drug-polymer dispersion was added in a $150 \mathrm{ml}$ liquid paraffin $(100 \mathrm{ml}$ light liquid paraffin $+50 \mathrm{ml}$ heavy liquid paraffin) containing $1.5 \mathrm{ml}$ span 80 and it was stirred with the help of mechanical stirrer at 1,500 revolutions per minute (rpm). After 10 and $40 \mathrm{~min}$, GA (25\% aqueous solution) was added and stirred continuously till $2 \mathrm{~h}$. Suspension of chitosan microspheres in paraffin oil, thus obtained was allowed to stand for $15 \mathrm{~min}$ to let the microspheres settle down under gravity. Supernatant was decanted and filtered. Microspheres obtained as residue were washed four times with solvent $\mathrm{n}$-hexane to remove traces of the oil. They were finally washed with water to remove excess GA. The microspheres were dried at $40^{\circ} \mathrm{C}$ for $24 \mathrm{~h}$. A total of nine batches, each in triplicate, were prepared as per the factorial design $\left(3^{2}\right)$. The amount of crosslinking agent and drug:polymer ratio was varied in batch no $\mathrm{CH} 1$ to $\mathrm{CH} 9$.

\section{Experimental design}

In this design, two factors were evaluated each at three levels and experimental trials were performed using all possible nine combination. In this present study, drug:polymer ratio $\left(\mathrm{X}_{1}\right)$ and volume of GA $\left(\mathrm{X}_{2}\right)$ were selected as independent variables. The $\%$ entrapment efficiency, particle size, and $\%$ in vitro drug release at $8 \mathrm{~h}$ was selected as dependent variables. A statistical model, incorporating interactive and polynomial terms was used to evaluate the response.

$\mathrm{Y}=\mathrm{b}_{0}+\mathrm{b}_{1} \mathrm{X}_{1}+\mathrm{b}_{2} \mathrm{X}_{2}+\mathrm{b}_{12} \mathrm{X}_{1} \mathrm{X}_{2}+\mathrm{b}_{11} \mathrm{X}_{1}^{2}+\mathrm{b}_{22} \mathrm{X}_{2}^{2}$

Where $\mathrm{Y}$ is the dependent variable, $\mathrm{b}_{0}$ is the arithmetic mean response and $b_{1}$ and $b_{2}$ are the estimated coefficient for the factor $\mathrm{X}_{1}$ and $\mathrm{X}_{2}$, respectively. The main effect $\left(\mathrm{X}_{1}\right.$ and $\left.\mathrm{X}_{2}\right)$ represents the average result of changing one factor at a time from its low to high value. The interaction term $\left(\mathrm{X}_{1} \mathrm{X}_{2}\right)$ shows how the responses changes when two factors are changed simultaneously. The polynomial terms $\left(\mathrm{X}_{1}^{2}, \mathrm{X}_{2}{ }^{2}\right)$ are included to investigate nonlinearity [Table 1 and 2].

\section{Evaluation of microspheres}

\section{Percentage entrapment efficiency}

A total of $25 \mathrm{mg}$ microspheres were crushed and dispersed in 100 $\mathrm{ml}$ phosphate buffer $\mathrm{pH} 6.8$ and sonicated for $20 \mathrm{~min}$. Dispersion was stirred on magnetic stirrer for $6 \mathrm{~h}$. The dispersion was filtered and drug content was analyzed spectrophotometrically at 262 $\mathrm{nm}$. The percentage drug entrapment efficiency was calculated using following equation:

$\%$ Entrapment Efficiency $=\frac{\text { Practical drug content }}{\text { Theoretical drug content }} \times 100$

\section{Particle size analysis}

Particle size analysis of drug-loaded chitosan microspheres was performed by optical microscopy using a compound microscope. A small amount of dry microspheres was suspended in purified

\begin{tabular}{|c|c|c|c|}
\hline \multirow[t]{2}{*}{ Independent variables } & \multicolumn{3}{|c|}{ Level } \\
\hline & -1 & 0 & +1 \\
\hline $\begin{array}{l}\mathrm{X} 1 \text { : Drug:polymer ratio } \\
\mathrm{X} 2 \text { : Volume of glutaraldehyde }(\mathrm{ml})\end{array}$ & $\begin{array}{c}1: 2(150 \mathrm{mg}: 300 \mathrm{mg}) \\
2\end{array}$ & $\begin{array}{c}1: 3(150 \mathrm{mg}: 450 \mathrm{mg}) \\
3\end{array}$ & $1: 4(150 \mathrm{mg}: 600 \mathrm{mg})$ \\
\hline
\end{tabular}

Dependent variables: $Y_{1}: \%$ entrapment efficiency, $Y_{2}:$ particle size, $Y_{3}: \%$ drug release at $8 \mathrm{~h}$

Table 2: Composition of batches nicorandil microspheres

\begin{tabular}{|c|c|c|c|c|c|}
\hline \multirow[t]{2}{*}{ Batch no. } & \multirow[t]{2}{*}{ Drug (mg) } & \multirow[t]{2}{*}{ Polymer (mg) } & \multicolumn{3}{|c|}{ Amount of cross linking agent glutaraldehyde (ml) } \\
\hline & & & After $10 \mathrm{~min}$ & After $40 \mathrm{~min}$ & Total glutaraldehyde \\
\hline $\mathrm{CH} 1$ & 150 & 300 & 1 & 1 & 2 \\
\hline $\mathrm{CH} 2$ & 150 & 450 & 1 & 1 & 2 \\
\hline $\mathrm{CH} 3$ & 150 & 600 & 1 & 1 & 2 \\
\hline $\mathrm{CH} 4$ & 150 & 300 & 1.5 & 1.5 & 3 \\
\hline $\mathrm{CH} 5$ & 150 & 450 & 1.5 & 1.5 & 3 \\
\hline $\mathrm{CH} 6$ & 150 & 600 & 1.5 & 1.5 & 3 \\
\hline $\mathrm{CH} 7$ & 150 & 300 & 2 & 2 & 4 \\
\hline $\mathrm{CH} 8$ & 150 & 450 & 2 & 2 & 4 \\
\hline $\mathrm{CH} 9$ & 150 & 600 & 2 & 2 & 4 \\
\hline
\end{tabular}


water $(10 \mathrm{ml})$. The suspension was ultrasonicated for $5 \mathrm{~s}$. A small drop of suspension thus obtained was placed on a clean glass slide. The slide containing chitosan microspheres was mounted on the stage of the microscope and diameter of at least 300 particles was measured using a calibrated ocular micrometer.

\section{In vitro drug release}

A total of $20 \mathrm{mg}$ nicorandil equivalent microspheres were weighed and filled in the empty capsule shells. Dissolution tests were performed in a USP Dissolution Tester Apparatus I (Basket method) at $37 \pm 0.5^{\circ} \mathrm{C}$. The baskets were rotated at a speed of 50 $\mathrm{rpm}$. The dissolution medium consisted of $0.1 \mathrm{~N}$ hydrochloric acid for the first $2 \mathrm{~h}$ and the phosphate buffer $\mathrm{pH} 6.8$ for 3-12 h $(900$ $\mathrm{ml}$ ). Aliquots of $5 \mathrm{ml}$ were withdrawn at different time intervals, filtered through Whatman filter paper and the content of nicorandil was determined spectrophotometrically at a wavelength of $262 \mathrm{~nm}$ using ultraviolet (UV) spectrophotometer. ${ }^{[1]}$

\section{In vitro release kinetics}

The drug release data of controlled-release microspheres was fitted to kinetics models, that is, zero order, first order, and Higuchi to find out drug release pattern and mechanism.

\section{Surface morphology}

Morphological characterization of the microspheres was carried out by using scanning electron microscopy (SEM) under higher and lower resolution.

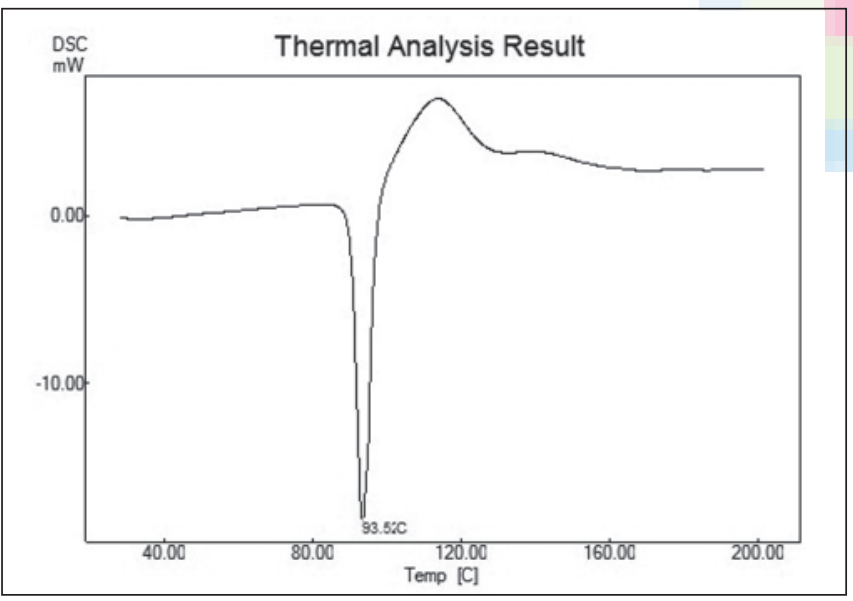

Figure 1: Differential scanning calorimetry (DSC) of nicorandil

\section{RESULTS AND DISCUSSION}

\section{Drug-excipient compatibility study by DSC}

DSC of the nicorandil and nicorandil:chitosan mixtures show endothermic peak at 93.52 and $92.68^{\circ} \mathrm{C}$, respectively. There was no change in the melting endotherm of the drug and drugchitosan mixture. So, it was concluded that drug and chitosan was compatible with the each other [Figures 1 and 2].

\section{Result of batches of nicorandil microspheres}

[Tables 3 and 4].

\section{Percentage entrapment efficiency}

[Table 5].

$\mathrm{Y}_{1}=+60.72+13.28 \mathrm{X}_{1}+3.72 \mathrm{X}_{2}+0.71 \mathrm{X}_{1} \mathrm{X}_{2}$

$$
-0.27 \mathrm{X}_{1}^{2}-1.60 \mathrm{X}_{2}^{2}
$$

The entrapment efficiency in chitosan microspheres was found 41.67-77.67. Here drug:polymer ratio and volume of GA had significant effect on entrapment efficiency.

From the above equation (2) shows that drug:polymer ratio and volume of GA had positive effect on entrapment of drug.

Effect of drug:polymer ratio: Entrapment of drug was increased

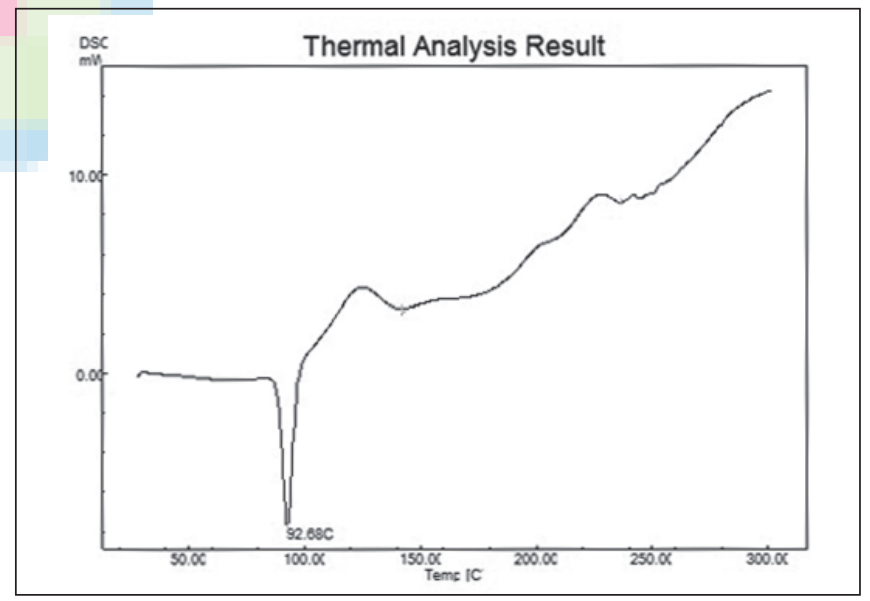

Figure 2: DSC of nicorandil:chitosan

Table 3: Observed response in $3^{2}$ full factorial design for nicorandil microspheres

\begin{tabular}{|c|c|c|c|c|c|}
\hline \multirow[t]{2}{*}{ Batch no. } & \multicolumn{2}{|c|}{ Independent variables } & \multicolumn{3}{|l|}{ Dependent variables } \\
\hline & $X_{1}(\mathrm{mg})$ & $\mathrm{X}_{2}(\mathrm{ml})$ & $Y_{1}: \%$ entrapment efficiency & $\mathrm{Y}_{2}:$ Particle size $(\mathrm{mm})$ & $\mathrm{Y}_{3}: \%$ drug release at $8 \mathrm{~h}$ \\
\hline $\mathrm{CH} 1$ & -1 & -1 & $41.67 \pm 1.43$ & $73.67 \pm 1.52$ & $101.91 \pm 1.58$ \\
\hline $\mathrm{CH} 2$ & 0 & -1 & $56.67 \pm 1.48$ & $93.33 \pm 1.63$ & $92.14 \pm 2.53$ \\
\hline $\mathrm{CH} 3$ & +1 & -1 & $67.33 \pm 1.53$ & $146.67 \pm 2.18$ & $71.08 \pm 2.67$ \\
\hline $\mathrm{CH} 4$ & -1 & 0 & $47.83 \pm 1.04$ & $68.67 \pm 0.58$ & $95.78 \pm 1.78$ \\
\hline $\mathrm{CH} 5$ & 0 & 0 & $60.67 \pm 1.89$ & $91.33 \pm 2.52$ & $79.11 \pm 2.23$ \\
\hline $\mathrm{CH} 6$ & +1 & 0 & $73.33 \pm 1.87$ & $137.33 \pm 2.12$ & $66.7 \pm 2.68$ \\
\hline $\mathrm{CH} 7$ & -1 & +1 & $48.83 \pm 0.76$ & $65.67 \pm 2.08$ & $83.22 \pm 2.41$ \\
\hline $\mathrm{CH} 8$ & 0 & +1 & $61.83 \pm 1.04$ & $83.00 \pm 2.00$ & $67.64 \pm 2.97$ \\
\hline $\mathrm{CH} 9$ & +1 & +1 & $77.33 \pm 1.97$ & $129.67 \pm 2.08$ & $55.16 \pm 2.23$ \\
\hline
\end{tabular}




\begin{tabular}{|c|c|c|c|c|c|c|}
\hline Parameter & Sum of Squares & df & Mean square & F-value & $P$-value & Remark \\
\hline \multicolumn{7}{|c|}{$Y_{1}$ (quadratic) } \\
\hline Model & 1152.21 & 5 & 230.44 & 334.30 & $<0.001$ & Significant \\
\hline Residual & 4.83 & 7 & 0.69 & & & \\
\hline \multicolumn{7}{|c|}{$Y_{2}$ (quadratic) } \\
\hline Model & 7843.43 & 5 & 1568.69 & 839.09 & $<0.001$ & Significant \\
\hline Residual & 13.09 & 7 & 1.87 & & & \\
\hline \multicolumn{7}{|l|}{$\mathrm{Y}_{3}$ (linear) } \\
\hline Model & 1878.68 & 5 & 375.74 & 89.66 & $<0.001$ & Significant \\
\hline Residual & 29.34 & 7 & 4.19 & & & \\
\hline
\end{tabular}

\begin{tabular}{lcc}
$\begin{array}{l}\text { Table 5: Regression analysis for } \mathbf{Y}_{\mathbf{1}} \\
\text { (\% entrapment efficiency) }\end{array}$ \\
\hline $\mathrm{R}^{2}$ & 0.9958 \\
Adjusted $\mathrm{R}^{2}$ & 0.9929 & \\
Standard deviation & 0.83 & \\
\hline Source & \\
\hline Source & Sum of squares & -value \\
\hline $\mathrm{X}_{1}$ & 1057.62 & $<0.001$ \\
$\mathrm{X}_{2}$ & 83.03 & $<0.001$ \\
$\mathrm{X}_{12}$ & 2.02 & 0.1310 \\
$\mathrm{X}_{1}^{2}$ & 0.2 & 0.6075 \\
$\mathrm{X}_{2}^{2}$ & 7.06 & 0.0151 \\
\hline
\end{tabular}

\begin{tabular}{lcc}
$\begin{array}{l}\text { Table 6: Regression analysis for } \mathbf{Y}_{\mathbf{2}} \text { (particle size } \\
\text { analysis) }\end{array}$ & \\
\hline $\mathrm{R}^{2}$ & 0.9983 & \\
Adjusted $\mathrm{R}^{2}$ & 0.9971 & \\
Standard deviation & 1.37 & \\
\hline Source & $\boldsymbol{P}$-value \\
\hline Source & Sum of squares & $<0.001$ \\
\hline $\mathrm{X}_{1}$ & 7049.34 & $<0.001$ \\
$\mathrm{X}_{2}$ & 0.0133 \\
$\mathrm{X}_{12}$ & 208.03 & $<0.001$ \\
$\mathrm{X}_{1}^{2}$ & 20.25 & 0.1904 \\
$\mathrm{X}_{2}{ }_{2}$ & 514.03 & \\
\hline
\end{tabular}

with increasing in drug:polymer ratio. It was occurred due to the increased in viscosity of aqueous phase with increasing the polymer concentration that stabilize droplets and which prevent out flow of drug during the hardening phase. ${ }^{[10]}$

Effect of GA: Here \% entrapment was increased with increasing the volume of GA. It can be explained by the higher degree of crosslinking occurred by higher concentration of GA. Increase in amount of GA produces much denser matrix due to increased crosslinking with chitosan that reduces the outflow of drug during stirring and increases the encapsulation efficiency. ${ }^{[11]}$

Particle size analysis

$\mathrm{Y}_{2}=+90.77+34.28 \mathrm{X}_{1}-5.89 \mathrm{X}_{2}-2.25 \mathrm{X}_{1} \mathrm{X}_{2}$ $+13.64 \mathrm{X}_{1}^{2}-1.19 \mathrm{X}_{2}^{2}$

From the above equation (3) shows that drug:polymer ratio had positive effect and volume of GA had negative effect on particle size. Effect of drug:polymer ratio, the particle size of the microspheres was found to be dependent on the concentration of chitosan [Table 6]. At lower concentration of chitosan (300 $\mathrm{mg}$ or $2 \%$ ), the mean particle size of microspheres observed was $73.67 \pm 1.53 \mu \mathrm{m}$. At medium concentration (450 mg or $3 \%$ ), the mean particle size was observed to be $93.33 \pm 1.53 \mu \mathrm{m}$. At higher concentration ( $600 \mathrm{mg}$ or $4 \%$ ), the chitosan solution was so viscous that it was difficult to pass through syringe and having mean particle size of $146.67 \pm 2.08 \mu \mathrm{m}$. Under the same preparation conditions, the droplets formed from the higher viscosity chitosan solution will be larger in size and hence result in formation of larger microspheres. The mean particle size of microspheres was significantly increased when high concentration of chitosan $(4 \%)$ was used. ${ }^{[1]}$

Effect of GA: As the volume of GA was increased, very slight decrease in the particle size of microspheres was observed. The mean particle size of microspheres prepared with 2,3 , and 4 $\mathrm{ml}$ of $\mathrm{GA}$ was $73.67 \pm 1.53,68.67 \pm 0.58$, and $65.67 \pm 2.08$ $\mu \mathrm{m}$, respectively. An increase in the volume GA can increase the efficiency of the stirrer due to decreased viscosity of the oil phase that may result in decreasing the particle size. Chitosan microspheres formulated with a higher GA concentration develop a greater number of covalent bonds, thus the polymeric matrix becomes stiffer, which is responsible for low microsphere size. ${ }^{[12]}$

In vitro drug release

$\mathrm{Y}_{3}=+79.17-14.66 \mathrm{X}_{1}-9.85 \mathrm{X}_{2}$

From the above equation (4) shows that drug:polymer ratio and volume of GA had negative effect on \% drug release [Table 7].

Effect of drug:polymer ratio: The in vitro drug release testing [Figure 3] exhibited a biphasic mode of drug release from the microspheres. There was an initial rapid release of drug, known as burst effect, due to fast dissolution of drug molecules attached to the surface of the microspheres, and a subsequent slow release phase, during which drug molecules present in the core of the microspheres diffused out [Figure 3]. The initial burst effect decreased with an increase in polymer concentration. Theoretically, the rate of drug release from microspheres decreases with an increase in polymer concentration due to the prolongation of the diffusion route of drug. It was due to as increased in polymer concentration the matrix wall of microspheres became thicker with less number of pores. The 
results of the present study are in accordance with figure (i.e., at $8 \mathrm{~h}$ for $\mathrm{CH} 1, \mathrm{CH} 2$, and $\mathrm{CH} 3$ are 101.94, 92.14, and 71.08\%, respectively in case of $2 \mathrm{ml}$ of GA) indicating a decrease in drug release with an increase in chitosan concentration. ${ }^{[12]}$

Effect of volume of GA: The nicorandil microspheres showed the drug release after $8 \mathrm{~h}$ in $\mathrm{CH} 2, \mathrm{CH} 5$, and $\mathrm{CH} 8$ batches were $92.14,79.11$, and $67.14 \%$, respectively. Microspheres prepared using $4 \mathrm{ml}$ of GA releases the drug slowly compared to the microspheres in which $2 \mathrm{ml}$ of GA is used. From the data it was found that the amount of GA had a strong effect on in vitro drug release. As the volume of GA increased the drug release decreased, which was well supported by the drug release profiles. Higher levels of GA favors the more cross-linking reaction and thus slower drug release. It can be explained by the increased cross liking density of chitosan with increased amount of GA. During the microspheres formation reaction takes place between $-\mathrm{NH}_{2}$ group of chitosan and $-\mathrm{COO}$ group of GA that forms new bonds and matrix structure form. Drug release from chitosan matrix occur only after swelling of the matrix, but increase in crosslinking density increases the hydrophobicity of chitosan matrix that increase the time for hydration and drug release decreases. ${ }^{[13,14]}$

The below figure [Figure 4] shows that $\mathrm{CH} 5$ batch was matched with the drug release profile with marketed formulation.

\section{Selection of optimized batch}

Based on the proposed target, range constraints set on the dependent variables were $60.00-77.33 \%$ for $\mathrm{Y}_{1}, 85.0-95.12 \mu \mathrm{m}$ for $\mathrm{Y}_{2}$, and $75.72-83.72 \%$ for $\mathrm{Y}_{3}$. The contour plots are evolved for each response which divides the plot surface into desirable and not desirable zone. A contour for each response is then

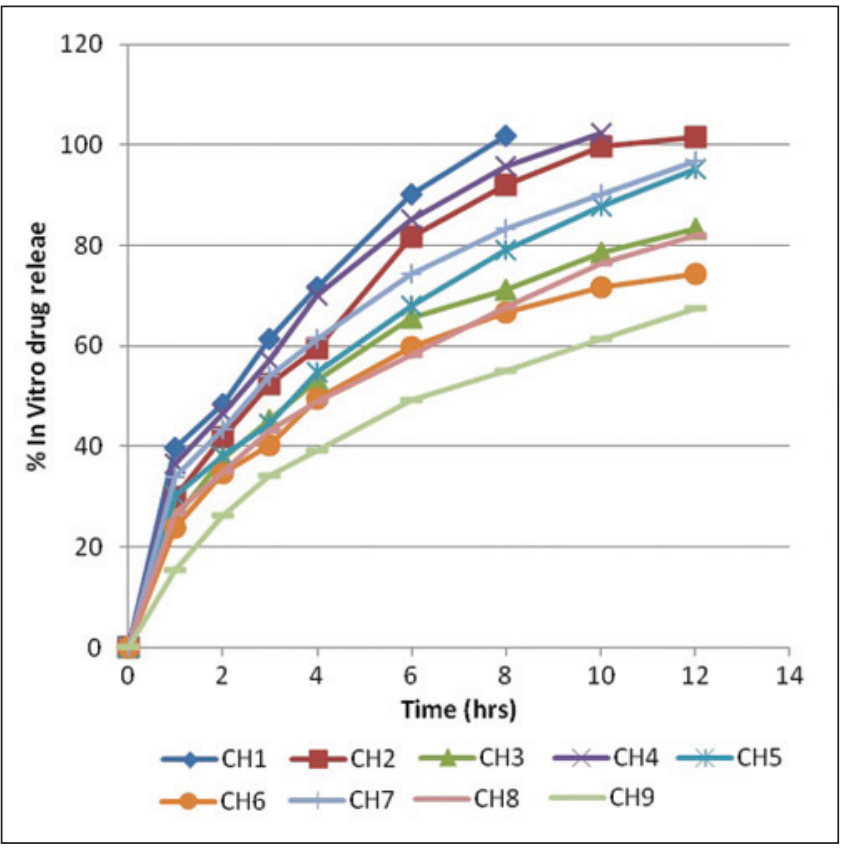

Figure 3: In vitro drug release profile of nicorandil microspheres batches superimposed to locate the area where the targets for the all response are achieved. Here in figure [Figure 5] shows the yellow area was the optimized area and batch $\mathrm{CH} 5$ was fall in the yellow region.

\section{Kinetic models}

The release kinetic of the formulation was checked by fitting the release data to various kinetic models. The release was best fitted to Higuchi model. Here, $n$ value was 0.4851 , so release mechanism was Fickian diffusion based [Table 8].

\section{Surface morphology}

From Figure 6a and b, it was observed that shape of microspheres seems to be spherical with fairly smooth surface.

\begin{tabular}{lll}
$\begin{array}{l}\text { Table 7: Regression analysis for } \mathbf{Y}_{3} \text { (in vitro } \\
\text { drug release at } \mathbf{8} \mathbf{~ h})\end{array}$ \\
\hline $\mathrm{R}^{2}$ & 0.9812 & \\
Adjusted $\mathrm{R}^{2}$ & 0.9774 & \\
Standard deviation & 1.89 & \\
\hline Source & & $P$-value \\
\hline Source & Sum of squares & $<0.001$ \\
\hline $\mathrm{X}_{1}$ & 1289.79 & $<0.001$ \\
$\mathrm{X}_{2}$ & 582.33 & \\
\hline
\end{tabular}

Table 8: Kinetic values obtained from different plots of batch $\mathrm{CH} 5$

\begin{tabular}{lcccc}
\hline Batch code & \multicolumn{4}{c}{ Regression values $\mathbf{( R}^{2}$ ) } \\
\cline { 2 - 5 } & $\begin{array}{c}\text { Zero } \\
\text { order }\end{array}$ & $\begin{array}{l}\text { First } \\
\text { order }\end{array}$ & $\begin{array}{c}\text { Higuchi square } \\
\text { root }\end{array}$ & $\begin{array}{c}\text { Korse } \\
\text { peppas }\end{array}$ \\
\hline $\mathrm{CH} 5$ & 0.9904 & 0.96 .23 & 0.9974 & 0.9946 \\
\hline
\end{tabular}

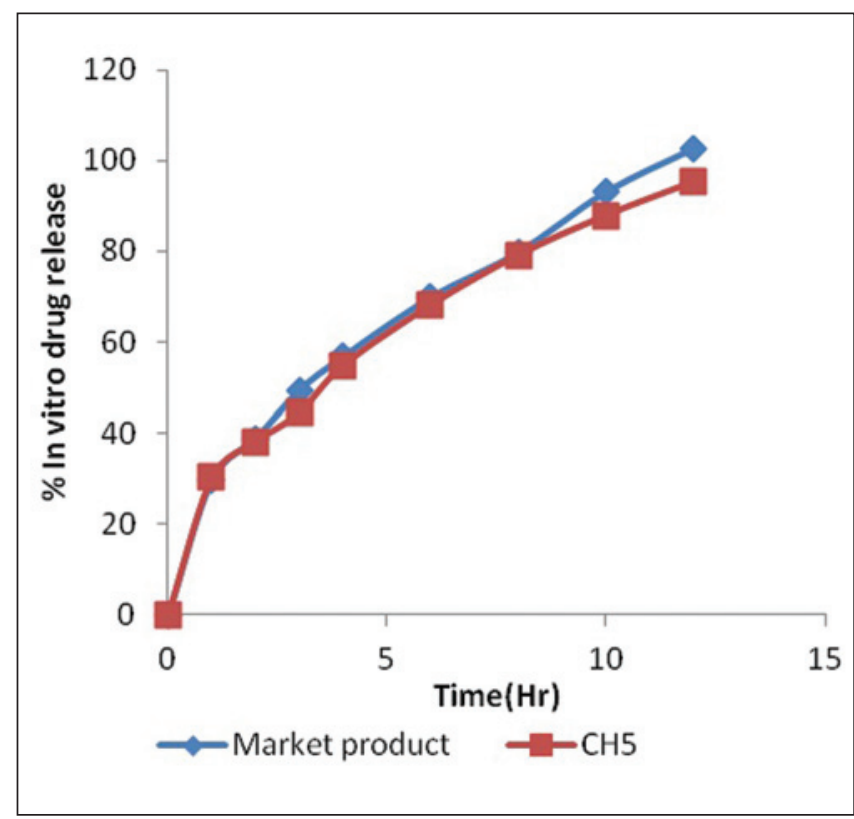

Figure 4: In vitro drug release profile of marketed formulation and batch $\mathrm{CH} 5$ 


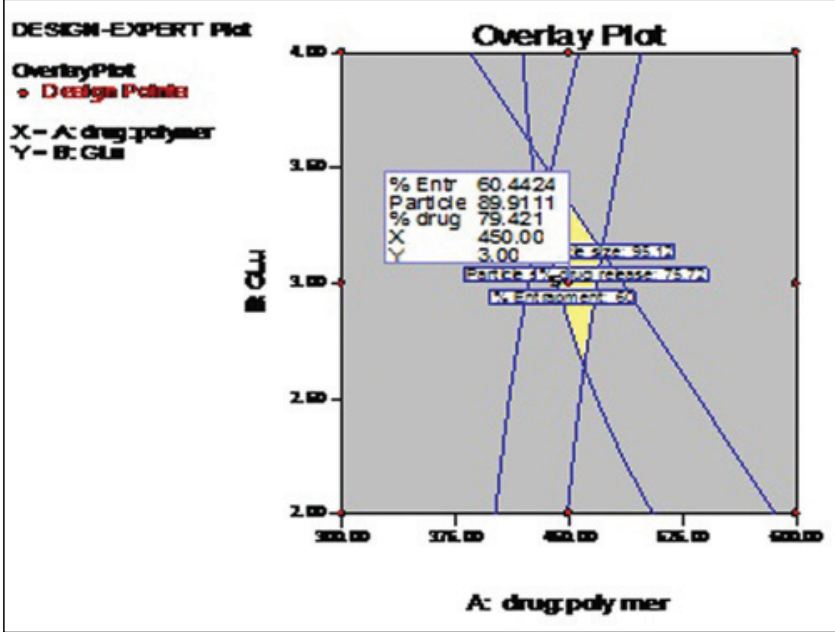

Figure 5: Overlay plot for optimization of nicorandil microspheres

\section{CONCLUSION}

Nicorandil microspheres were prepared successfully by emulsion crosslinking method. Drug:polymer ratio and volume of GA had significant effect on various parameters like percentage entrapment efficiency, particle size, and \% in vitro drug release. It was found that increase in the drug:polymer ratio resulted an increase in particle size and \% entrapment efficiency. Here, \% drug release rate was decreased with increasing the concentration of polymer and volume of GA. The batch $\mathrm{CH} 5$ showed the drug release $96 \%$ after $12 \mathrm{~h}$ which was matched with market formulation release profile. From the SEM study, it was observed that microspheres were spherical and fairly smooth surface.

\section{ACKNOWLEDGEMENTS}

The authors thank to Torrent Research Center for providing gift sample of nicorandil.

We are grateful for financial support provided from the A. K. Raval charitable trust.

\section{REFERENCES}

1. Abdelbary GA Tadros MI. Design and in vitro/in vivo evaluation of novel nicorandil extended release matrix tablets based on hydrophilic interpolymer complexes and a hydrophobic waxy polymer. Eur J Pharm Biopharm 2008;69:1019-28.

2. Reddy KR, Mutalik S, Reddy S. Once-daily sustained-release matrix tablets of Nicorandil: Formulation and in vitro evaluation. AAPS PharmSciTech 2003;4:147-56.

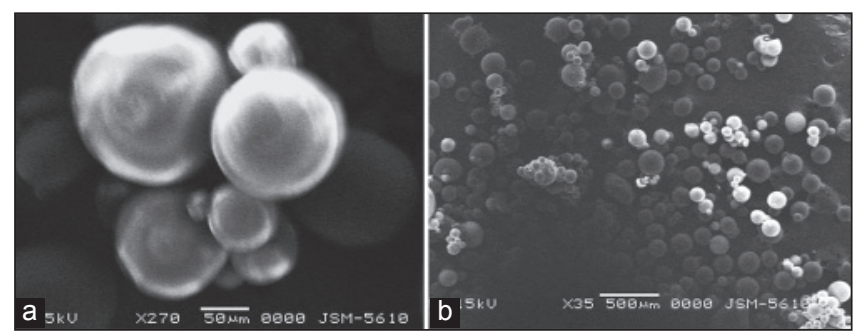

Figure 6: (a) Scanning electron microscopy (SEM) of Nicorandil microspheres. (b) SEM of nicorandil microspheres

3. Hiremath JG, Rajeshkumar VR, Narhare J. Pharmaceutical aspects of nicorandil. Int J Pharm Pharm Sci 2010;2:24-9.

4. Capan Y, Jiang G, Giovagnoli S, Na KH, Deluca PP. Preparation and characterization of poly (D, L-lactide-co glycolide) microsphere for controlled release of human growth hormone. AAPS Pharm Sci Tech 2003;4:147-56.

5. Gohel MC, Amin AF. Formulation optimization of controlled release of diclofenac sodium microspheres using factorial design. J Control Release 1998;51:115-22.

6. Khare P, Jain SK. Influence of rheology of dispersion media in the preparation of polymeric microspheres through emulsification method. AAPS Pharm Sci Tech 2009;10:1295-300.

7. Kotadiya R, Patel V, Patel H, Koradiya H. Effect of cross-linking on physicochemical properties of chitosan mucoadhesive microspheres. Int J Green Pharm 2009;3:58-62.

8. Hassan EE, Parish RC, Gallo JM. Optimized formulation of magnetic chitosan microspheres containing the anticancer drug, oxantrazole. Pharm Res 1992;9:390-7.

9. Thanoo BC, Sunny MC, Jayakrishnan A. Cross-linked chitosan microspheres: Preparation and evaluation as a matrix for the controlled release of pharmaceuticals. J Pharm Pharmacol 1992;44:283-6.

10. Denkba EB, Seyyal ME, Skin EP. Implantable 5-fluorouracil loaded chitosan scaffolds prepared by wet spinning. J Membrane Sci 2000;172:33-8.

11. Patil SB, Sawant KK. Chitosan microspheres as a delivery system for nasal insufflations. Colloids Surf B Biointerfaces 2011;84:384-9.

12. Ghulam Murtaza G, Mahmood A, Izhar H. Evaluation of cefiximeloaded chitosan microspheres: Analysis of dissolution data using DDSolver. Dissolution Technol 2012;13-20.

13. Jameela SR, Kumary TV, Lal AV, Jayakrishnan A. Progesteroneloaded chitosan microspheres: A long acting biodegradable controlled delivery system. J Control Release 1998;52:17-24.

14. Thakkar HP, Murthy RR. Effect of cross-linking agent on the characteristics of celecoxib loaded chitosan microspheres. Asian J Pharm 2008;2:246-51.

How to cite this article: Patel KS, Patel MB. Preparation and evaluation of chitosan microspheres containing nicorandil. Int $\mathrm{J}$ Pharma Investig 2014;4:32-7.

Source of Support: We are grateful for financial support provided from the A. K. Raval charitable trust. Conflict of Interest: None declared. 